\title{
Adaptação ao meio líquido: Fundamentos Pedagógicos da Natação
}

\author{
Adaptation to the liquid environment: \\ Pedagogical Fundamentals of Swimming
}

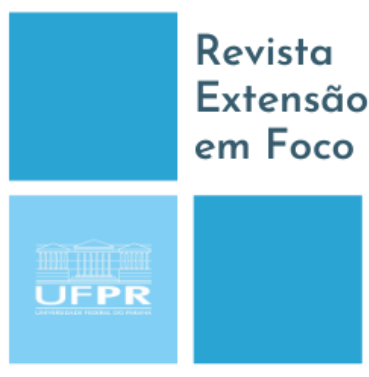

ISSN $2358-7180$

\author{
Antonio Marcos de Souza ${ }^{1}$, Nádia Ligianara Dewes Nyari², Moacir Juliani ${ }^{3}$
}

RESUMO

O presente estudo apresenta a história da modalidade, sua evolução, adaptação e fundamentos voltados à natação, sendo uma modalidade que tem sido procurada por todas as faixas etárias, por seus vários benefícios para a saúde é recomendada a todas as idades. À maior procura por esta prática esportiva, é realizada por indivíduos que não sabem sobreviver no ambiente líquido sendo bebês e crianças. Acidente por Afogamento (drowning) é definido como resultado de asfixia por imersão ou submersão em qualquer meio líquido e seus índices têm aumentado significativamente no Brasil, cada vez mais crianças, principalmente meninos com idade inferior a cinco anos segundo a Sociedade Brasileira de Pediatria (SBP). Entretanto esse problema poderia ser evitado com medidas de prevenção, cuidado e supervisão, já que esse grupo de indivíduos são mais vulneráveis, inexperientes e não conseguem prever a verdadeiro risco nas ações, além da enorme curiosidade, falta de coordenação motora e algumas peculiaridades anatômicas ou orgânicas. Mas este tipo de acidente não acontece apenas em crianças, mas também com adolescentes e adultos, especialmente em piscinas, sendo uma ameaça mundial para a saúde e bem-estar das crianças e está atrelado a um grande transtorno emocional e abatimento psicológico conforme o Ministério da Saúde. Nesse sentido, o objetivo do presente estudo visa avaliar as principais dificuldades da adaptação ao meio líquido em diferentes faixas etárias.

Palavras-chave: Natação. Adequação. Desafio. Aprendizagem. Educação.

\section{ABSTRACT}

The present study presents the history of the sport, its evolution, adaptation and fundamentals focused on swimming, being a sport that has been sought by all age groups, for its various health benefits and recommended for all ages. The greatest demand for this sports practice is carried out by individuals who do not know how to survive in the liquid environment as a baby and children. Drowning accidents are defined as the result of asphyxiation by immersion or submersion in any liquid medium and its rates have increased significantly in Brazil, more and more children, especially boys under the age of five, according to the Brazilian Society of Pediatrics (SBP). However, this problem could be avoided with prevention, care and supervision measures, since this group of individuals are more vulnerable, inexperienced and cannot predict the real risk in actions, in addition to the enormous curiosity, lack of

\footnotetext{
${ }^{1}$ Graduação em Educação Física. Centro Universitário UniLaSalle Lucas Rio Verde, MT, Brasil. E-mail: marcossouza@ hotmail.com. Orcid: https://orcid.org/0000-0002-6083-0263.

${ }^{2}$ Doutora. Engenharia de Alimentos. Universidade Regional Integrada do Alto Uruguai e das Missões URI - Campus de Santo Ângelo, RS. Professora do Ensino Superior do Centro Universitário UniLaSalle Lucas Rio Verde, MT, Brasil. E-mail: nadialigianara@hotmail.com. Orcid: http://orcid.org/0000-00030237-5116

${ }^{3}$ Doutor. Doutorando no Programa de Pós Graduação em Educação - PPGE - Universidade Federal de Mato Grosso - UFMT. Professor do Ensino Superior do Centro Universitário UniLaSalle Lucas Rio Verde, MT, Brasil. E-mail: moacir.juliani@unilalasallelucas.edu.br. Orcid: https://orcid.org/0000-0002-9940$937 \mathrm{X}$.
} 
motor coordination and some anatomical or organic. But this type of accident does not only happen in children, but also in teenagers and adults, especially in swimming pools, being a global threat and for the health and well-being of children and it is associated with a great emotional disorder and psychological shock according to the Ministry of Health. In this sense, the objective of the present study is to evaluate the main difficulties of adapting to the liquid environment in different age groups.

Keywords: Swimming. Adequacy. Challenge. Learning. Education.

\section{INTRODUÇÃO}

A natação é uma modalidade de exercício físico de grande importância e altamente recomendável em qualquer idade, sendo reconhecida e praticada atualmente por um número expressivo de indivíduos, procurada é recomendada para todas as faixas etárias. Conforme a Sociedade Brasileira de Pediatria trata- se de uma atividade, saudável, completa e a única, podendo ser praticada desde o nascimento.

Natação enquanto prática esportiva pressupõe transpor um percurso no menor tempo, ou de competição, como em provas esportivas: nado crawl, nado costa, nado peito, nado borboleta, revezamentos e Medley (quatro estilos de nado) ou simplesmente o ato de deslocar-se no meio líquido. CORREIA et al., 2019).

Desenvolvendo habilidades motoras complexas, socialização e de relacionamentos, estabelecendo o conceito de brincar e aprender a se defender dentro de água, desenvolvendo a autonomia da criança no meio aquático, segurança - já que saber nadar é também uma questão de sobrevivência (ALENCAR, 2018).

Segundo os autores, as aulas de natação têm uma influência positiva na prevenção ao afogamento, principalmente a Sobrevivência Aquática, já que os indivíduos desenvolvem adaptação ao meio líquido, de sustentação na superfície da água, autonomia e independência. Para Machado (1978) esse aprendizado envolve a ambientação ao meio líquido, flutuação, respiração, propulsão e mergulho, contudo todas as atividades envolvendo anteriormente uma fase de adaptação, como: exercícios de confiança, respeitando as potencialidade de aprendizado da criança (SANTANA, 2001; HEISE \& LIMA, 2016).

Segundo Junior (CAMPINAS, 1998) o meio líquido é a origem da vida. No entanto, na literatura há poucos trabalhos que reportam o ensino e como ocorre o trabalho com crianças do profissional de educação no meio aquático. Para Gomes (1995), Costill et al. 
(1992) e Lima (2006) o ponto primordial é a adaptação ao meio líquido devem ser adequadas à capacidade perceptivo-motora, proprioceptiva, sensorial e à consciência corpórea-espaço-temporal do indivíduo, além da individualidade biológica, psicológica e sócio comportamental, para que se possibilite a progressão pedagógica no sentido do mais simples ao complexo (JUNIOR \& LOPES, 2018; CORREIA et al., 2019).

Sendo assim, é primordial que o profissional educador esteja bem atento a tudo e preparado para eventuais ocorrências, buscando sempre o cuidado redobrado e a atenção voltada aos alunos, como utilizar -se de formas lúdicas e estratégias inteligentes, com aplicação de brincadeiras, situações imaginárias e criativas, tendo uma relação de confiança (SOARES, 2014). Nesse sentido, o objetivo do presente estudo visa avaliar as principais dificuldades da adaptação ao meio líquido em diferentes faixas etárias.

\section{REFERENCIAL TEÓRICO}

De acordo com a Federação Internacional de Natação (FINA), entidade vinculada ao Comitê Olímpico Internacional (COI), não se sabe ao certo quando a prática de natação teve início realmente. Para Catteau \& Garoff (1990) a origem se confunde com a da própria humanidade, referindo-se a sua prática para subsistência e sobrevivência.

Atualmente essa prática está disseminada pelo mundo, presente especialmente nas instituições de ensino como componente curricular de ensino, sobretudo trazendo grandes benefícios para saúde e seu desenvolvimento psíquico e motor, além de outras atividades dentro do ambiente aquático como a hidroginástica, fisioterapia, etc. Para Mansolo (1986), a natação hoje é uma atividade que não só visa à sobrevivência e a subsistência, mas proporciona o prazer e ajuda no desenvolvimento integral do aluno. Por essas e outras razões, o meio aquático é responsável por proporcionar grandes benefícios, atingindo todas as faixas etárias, de bebês à terceira idade.

Contudo é um esporte ser indicado para os asmáticos e recomendado para prevenção de doenças cardiorrespiratórias, ampliando ainda a capacidade respiratória do indivíduo, usada para fortalecimento dos músculos e da parede torácica, possibilitando assim a dilatação dos brônquios, aprimorando o sistema respiratório e aumentando a sua oxigenação, sobretudo o aumento do volume sanguíneo, melhorando o raciocínio lógico, 
concentração e o trabalho de coordenação motora (FERNANDES \& LOBO DA COSTA, 2006; DE SIMONE, 2017).

Atividade considerada sem impacto, indicada para indivíduos com desvio de vértebra, hérnia de disco e bico de papagaio, melhorando assim a qualidade de vida e muito indicada por profissionais da saúde. Mas ela exige do professor o conhecimento de como se desenvolve o processo aprendizagem e das habilidades motoras necessárias para o seu desenvolvimento (AMARAL et al, 2005; MACHADO, 2006; NIESWALD et al., 2019).

Corroborando com esse fato, Esteves (2018) relata que alguns momentos adaptar se ao ambiente aquático pode a despertar medo e inseguranças principalmente nas crianças, por ser um ambiente diferente, por ter um grande volume de água. Causando situações inconvenientes e desconfortos, já que mesmo o indivíduo consiga permanecer em pé na piscina, pode despertar o medo em se afogar, devido a algum trauma ou por ainda por não ter desenvolvido nenhuma habilidade aquática como flutuação ventral ou dorsal.

O indivíduo contendo essas características irá ser estimulado inicialmente pelas habilidades aquáticas básicas, começando por aceitar água no rosto, submergir o rosto na água soltando bolhão, se sustentando na borda da piscina e também desenvolvendo a sustentação, exercício este em que o indivíduo desenvolve autonomia para executar a flutuação ventral e dorsal onde depois ele também iniciará a se movimentar com auxílio de macarrão ou outros instrumentos, em que ele de acordo com seu tempo, começará os movimentos de forma rudimentar no ato de conseguir se virar para sobreviver no ambiente aquático. Embora com o passar do tempo começa a criar certa independência do macarrão, prancha ou halter, conseguindo dar continuidade aos movimentos iniciais na piscina de acordo com Gallahue (2003) (GRECO \& BENDA, 1998; CORREA \& MASSAUD, 1999).

Fundamentos Pedagógicos do Nado Crawl

O estilo crawl da natação é conhecido no mundo todo por ser de mais fácil aprendizagem, sendo atualmente a modalidade de nado praticada nas provas de nado livre (DURAN, 2005). Essa técnica é voltada variam de acordo com o estilo, onde provas denominadas longas como 400M livre, 800M livre, Maratonas aquáticas em mar aberto e assim por diante, é recomendado se usar a técnica de uma braçada curta, deixando os 
cotovelos mais elevados que os ombros. Já em provas curtas rápidas como 50M livre, 100M livre e 200M livre, o recomendado aos atletas é abraçada pelo (braço todo esticado), por sua recuperação ser mais rápida que a braçada curta, quando a braçada entra na fase aérea ela é mais rápida que a fase submersa (DE VARGAS \& FRANKEN 2020).

As técnicas de braçada são eficientes a partir do momento em que o aluno já tenha atingido um grau de aperfeiçoamento perante a natação, mas na fase de iniciação o aluno começa a desenvolver a técnica mantendo os cotovelos elevados para também coordenar com a fase de apoio para a respiração segundo Oliveira (2015). Para se chegar ao aperfeiçoamento é necessário desenvolver os fundamentos que englobam esta modalidade de natação, a respiração lateral e bilateral, pernada e braçada. Para a pernada do nado crawl, as pernas devem se movimentar toda esticada enquanto os pés devem permanecer relaxados durante a execução do nado, empurrando a água para baixo e para cima, assim, é possível se ter maior propulsão durante a execução do nado (DE CARVALHO \& MACIEL, 2018).

Fundamentos Pedagógicos do Nado Costa - Peito - Borboleta

$\mathrm{Na}$ execução da braçada do nado costas é desempenhada em duas fases de braçada, sendo na fase aérea e na fase submersa. No início da fase aérea o braço se mantém esticado, a mão acompanhando o movimento inicia a fase aérea saindo com o polegar, mas ao chegar na orelha a palma da mão vira - se para a entrada do dedo mindinho. Na fase submersa é realizada uma alavanca, em seu início o braço fica semiflexionado para empurrar a água em direção aos pés e concluindo com a palma da mão voltada para baixo, assim o deslocamento do indivíduo por essa técnica passa a ser mais eficiente (MAGLISCHO, 1999; TEIXEIRA, 2015).

Na execução do nado peito ocorre de forma simultânea, por ter ação de pernas ao mesmo e de braços tendo a ação do lado direito do cérebro e esquerdo, exigindo assim uma maior coordenação para se executar o nado. A sequência pode iniciar pela pernada, que para se executar, os movimentos da pernada são em semicírculos tendo um intervalo de uma pernada para outra, assim a cada pernada realizada o aluno irá deslizar. A braçada também tem a ação simultânea, realizando os movimentos de fura e abre, retornando ao ponto inicial. A cabeça que estava entre os braços, sai da água quando começa a abertura dos braços e logo retorna quando os braços começam a fechar na altura do peito (SABINO, 2013; DE MELO et al., 2020). 
Este aspecto demonstra que os estilos de natação podem ter alterações com o passar do tempo, o que nos leva a pensar o quanto a metodologia de trabalho e os estudos podem criar estilos cada vez mais eficientes no processo de se deslocar corporalmente no meio líquido.

O nado borboleta normalmente é o último a ser protagonizado nas aulas de natação, por exigir maior coordenação e esforço físico, esta modalidade é inserida após o aluno ter aperfeiçoado todos os outros nados. Sendo também um nado simultâneo, a técnica da braçada e semelhante a do nado crawl, mas tendo que estar em execução conjunta dos dois braços, além disto, tem a pernada em que para se executar é necessário ter a ação ondulatória iniciando no quadril e depois batendo as pernas no final.

Para cada braçada do nado borboleta são necessárias duas pernadas para fazer este ciclo. Assim para Silveira (2011) O nado borboleta é considerado uma técnica simultânea, quanto à ação dos membros superiores e membros inferiores, e uma técnica descontínua em relação às ações propulsivas de braços e pernas. É o nado mais complexo, e é recomendado seu ensinamento após o aperfeiçoamento dos outros nados, sendo o último nado a ser aprendido pelos indivíduos, pois, é exigido um grau de coordenação motora maior além da força física exercida durante o nado.

\section{METODOLOGIA}

A presente pesquisa classifica-se como qualitativa, com abordagem que permite o aprofundamento da investigação no que se refere ao fenômeno em estudo e suas relações através do método indutivo e classificado conforme os objetivos de pesquisa como descritiva. Envolve o uso de técnicas padronizadas de coleta de dados: questionário e observação sistemática (GIL, 2008).

Os procedimentos são classificados como uma pesquisa de campo, no qual é possível aprofundar sobre uma realidade específica. Realizada por meio da observação direta das atividades do grupo estudado e de entrevistas com informantes para captar as explicações e interpretações do que ocorre naquela realidade (GIL, 2008).

O público alvo da pesquisa foram onze aprendizes, sujeitos envolvidos com a atividade de natação, com faixa etária entre três a setenta e cinco anos, de ambos os sexos, 
com experiência e adaptação ao ambiente líquido de um mês a um ano de atuação e frequência de um à cinco vezes semanais. A coleta dos dados foi realizada através de questões mistas, contendo perguntas abertas e fechadas e organizadas e analisadas de forma a haver uma melhor compreensão sobre o tema.

\section{RESULTADOS E DISCUSSÕES}

Para identificar as dificuldades de adaptação ao meio líquido na fase inicial está apresentado na Figura 1 (a) e (b) mostra as vivências com o ambiente líquido antes das aulas de natação (Antes de praticar as aulas de natação você ou seu filho (a) tinham alguma vivência com o ambiente líquido?) e a (c) exibe os resultados com relação ao trauma desenvolvido a partir do ambiente aquático (Você ou seu filho (a) desenvolveu algum trauma por experiência no ambiente aquático?).

Figura 1 - Dificuldades na adaptação ao meio líquido na fase inicial (a), as vivências com o ambiente líquido antes das aulas de natação (b) e o Trauma desenvolvido a partir do ambiente aquático $(\mathrm{c})$.

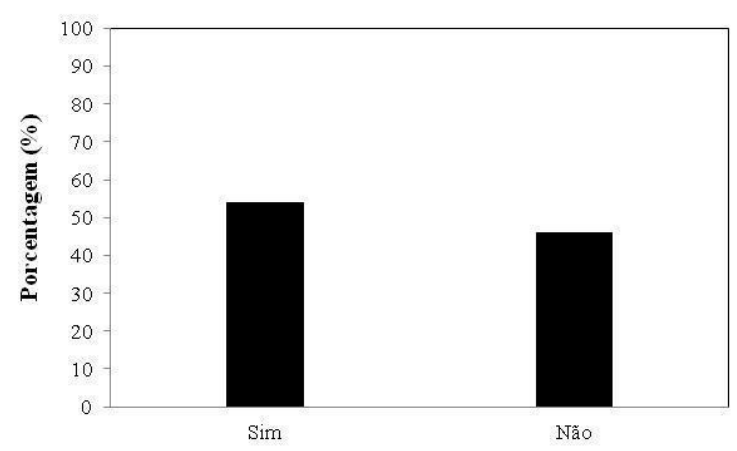

(a)

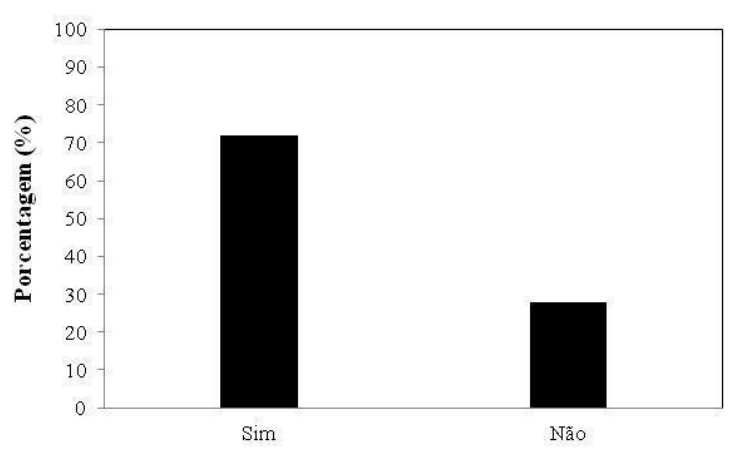

(b)

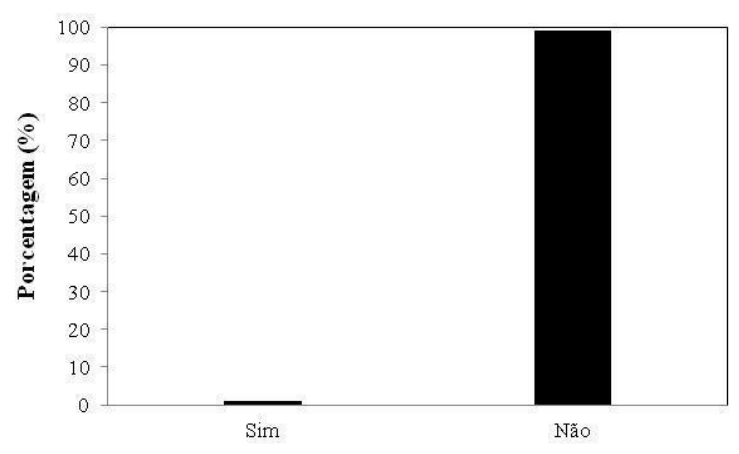

(c) 
Dos resultados 54\% da Figura 1 (a) responderam sentir dificuldades na adaptação ao meio líquido na fase inicial da natação. Justificando entre os entrevistados E1, E2, E3, E4, E10 e E11 haver dificuldade de colocar o rosto na água. "Meu Filho apresentou receio com o volume da água na piscina, assustando-se; Medo de se afogar; Insegurança. Eu tinha muito medo de me afogar e não sabia respirar direito e Eu tinha muito medo da água". No entanto 46\% disseram que não, E5, E6, E7, E8 e E9 no qual justificaram adaptar-se facilmente com a natação "Sempre gostou muito de água, seus medos foram facilmente superados e Não teve dificuldade".

Dos resultados $72 \%$ da Figura 1 (b) responderam que sim, onde E1, E2, E4, E6, E7, E8, E9 e E10 justificaram "Participava no convívio com a família na prática de entrar na água em banheiras ou rios; Em casa, piscina, mas sempre com boia; Piscina no sitio; Tenho piscina em casa e Desde pequeno nadava na piscina em casa; Já ia à piscina em casa e Brincava na piscina, apenas fazia bolhão”. No entanto, 28\% rebatem que não, E3, E5 e E11 explicam que "Não teve dificuldade em banho, sempre gostou; Por falta de oportunidade e Não teve dificuldade em banho, sempre gostou”.

Dos pesquisados 100\% da Figura 1 (c) relatam que não, onde E1, E2, E3, E4, E5, E6, E7, E8, E9 e E10, E11 revelam que "Ela vivenciou nenhum tipo de trauma; Os profissionais sempre tiveram muito cuidado, respeitando seu tempo de desenvolvimento; Não vivenciou isso e Na adolescência tive sonhos que me afogava”.

É possível constatar que a maioria dos indivíduos da pesquisa vivenciaram dificuldades em relação à adaptação ao meio líquido nos momentos iniciais da natação. Estas dificuldades situavam-se em relação ao tamanho da piscina e a quantidade de água. A dificuldade encontrada foi de que os alunos tinham medo da água por saber que poderiam se afogar e o grande volume de água despertou-lhes insegurança dificultando o processo inicial de adaptação ao meio líquido.

Relataram também a questão do medo que normalmente está associado às vivências e experiências pregressas do aprendiz e este último, relatam que os aprendizes que tiveram facilidade se destacaram por gostar da água, sendo um facilitador ao processo de adaptação ao meio líquido (DE AZEVEDO \& FERREIRA, 2020).

Essa adaptação pode ser influenciada pelos pais e familiares do aprendiz, no que se menciona quanto aos temores e cuidados preventivos aos acidentes e afogamentos, além da ansiedade acontecer de forma rápida no processo de aprendizagem, desconsiderando assim o ritmo da criança ou do aprendiz. Para Rosa Neto (2002) "Vale lembrar que cada criança tem seu ritmo, não só por ser única, mas, também, pela 
maturação dos centros nervosos que é diferente em cada uma das crianças". Assim, familiares e professores precisam ter ciência destes aspectos para que a adaptação ocorra de forma natural (MARTINS et al., 2015).

Entretanto, a partir dos relatos constatou-se que antes de iniciar as práticas de natação a maioria dos indivíduos já tinha vivenciado alguma prática no ambiente líquido. O que facilitou a sua adaptação e o desenvolvimento. Fernandes \& Lobo da Costa (2006) descreve que é fundamental que o foco do ensino passe a ser o processo do aprender a nadar e não o seu produto, qual seja, o domínio mecânico dos estilos consagrados de nado.

Sobre o primeiro contato com a água, Prado (2002) relata que geralmente, no primeiro contato com o meio líquido o aluno (a) sente alterações em seu corpo, que são na maioria das vezes normal. É necessária uma adaptação gradual com a finalidade de evitar o conhecido "trauma de água".

Todos os indivíduos não tiveram nenhum trauma por experiência no ambiente aquático, sendo este um dos fatores que comprometem a adaptação e aprendizagem do indivíduo para a natação. Mesmo assim houve relato de que, por o indivíduo estar na fase inicial de natação, foi necessário que o professor enquanto ministrava a aula, trabalhava com cuidado e cautela para que a criança no momento da aula não pudesse passar por algum tipo de acidente, pois até mesmo dormindo, é possível que o indivíduo sonhe que está passando por um afogamento e criar certo receio da prática aquática (SILVA et al., 2016). Segundo os autores, a experiência intra uterina influencia no prazer que o ser humano sente nas atividades realizadas no meio líquido (DE MELO et al., 2020).

No entanto na Figura 2 (a) exibe as Dificuldades de aprendizagem da Natação diferentes faixas etárias dos aprendizes (Em relação à aprendizagem, você ou seu filho (a) encontrou dificuldades na aprendizagem de algum estilo?) e (b) mostra o Trabalho e Movimentos de Pernas (Em relação a aprendizagem do trabalho de pernas, encontrou dificuldades?).

Figura 2 - Dificuldades de aprendizagem da Natação (a) e o Trabalho e Movimentos de Pernas (b). 


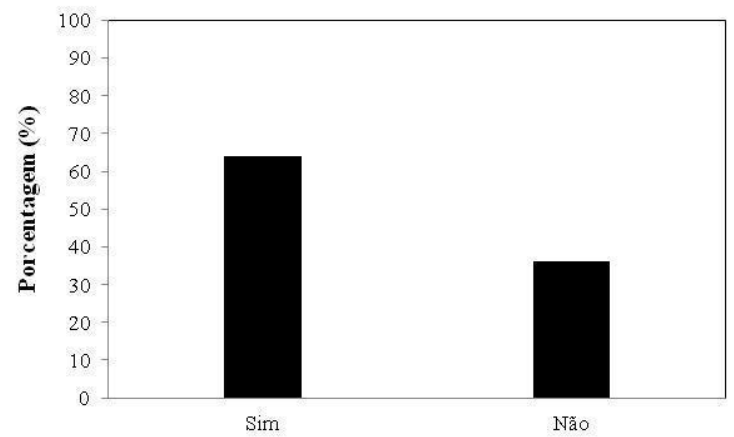

(a)

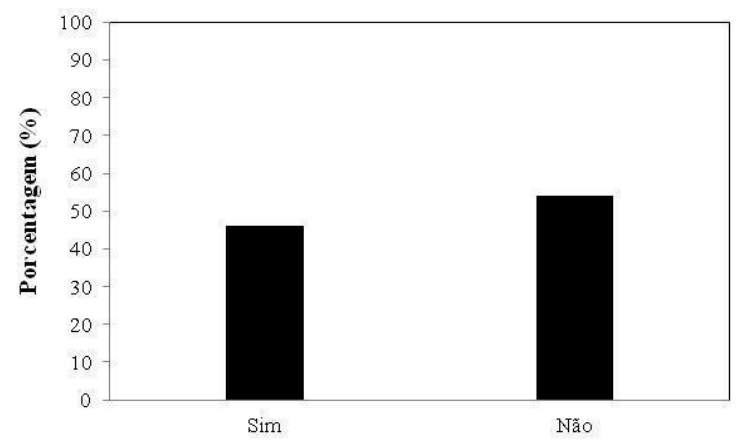

(b)

Dos resultados $64 \%$ da Figura 2 (a) foram positivos, argumentando "Treinamento, superação do medo; Por insegurança não conseguiu executar corretamente os exercícios propostos"; Crawl. Com auxílio do material, exemplo macarrão e prancha; Costas e Borboleta. Costas tiveram dificuldade em flutuar. Trabalho de flutuação. No Borboleta teve dificuldade na técnica. O professor está trabalhando passo a passo do nado ondulação, braçada e pernada; Costas. Teve dificuldade, pois teve problemas no ouvido; Crawl. Praticando; Crawl e Ainda tenho dificuldade. Já 36\% disseram que não, onde E1, E2, E8 e E9 descreveram que "Porém, meu filho ainda está aprendendo os movimentos iniciais".

Dos resultados apresentados, 46\% da Figura 2 (b) responderam que sim, onde E3, E4, E5, E6 e E11 “Coordenação Motora Borboleta. Dificuldade em mantê-la unidas e ondulando com propulsão; Pernas e braços juntos tenho dificuldade”. Além disso, 54\% avaliaram que não, no qual E1, E2, E7, E8, E9 e E10 disseram que "Foi tranquilo".

É possível constatar que os indivíduos da pesquisa tiveram dificuldades no processo de aprendizagem de algum estilo de nado. As dificuldades apontadas são de que os indivíduos se sentem inseguros, têm medo de executar as atividades quando ainda estão na fase inicial de aprendizagem, também, o aprendizado do aluno se dá pela sua frequência com as aulas de natação, mas alguns por intermédio de doenças como dor de ouvido acabam tendo que se ausentar das aulas. Outras dificuldades são encontradas na aprendizagem de um estilo novo como o nado costas e borboleta, pois são dados que exigem força física, coordenação e tem um nível de complexidade maior em sua execução.

Em relação às facilidades no aprendizado de algum estilo de natação são aquelas que ainda estão desenvolvendo a técnicas básicas de cada nado e tomaram gosto pelas aulas ainda na fase inicial. Constatou-se que os indivíduos não encontraram dificuldades em aprender os movimentos de pernadas, sendo que para ter uma melhor propulsão e 
velocidade nos nados a serem executados, é necessário se ter uma pernada apropriada tecnicamente para ter um melhor desempenho quando se executar o nado de maneira global.

Segundo Silva (2016) Considera-se que a infância é uma fase determinante no processo de aquisição de habilidades e capacidades motoras, tanto por suas alterações biológicas serem aceleradas como pela elevada capacidade de ajustar os estímulos ambientais recebidos (DE AZEVEDO \& FERREIRA, 2020). Aos indivíduos que encontraram problemas, a maioria estão na fase em que os nados se tornam mais complexos, e destacam a dificuldade em ligar pernas e braços do nado crawl e aprender outros estilos de nados que exigem uma melhor flutuação dorsal como no nado costas e o borboleta que se exige uma maior força física para se executar a pernada de estilo ondulatório.

A Figura 3 (a) apresenta a aprendizagem do trabalho de braços (Em relação à aprendizagem do trabalho de braços (braçada), encontrou dificuldade?) e (b) exibe o trabalho de Respiração (Em relação à aprendizagem da respiração, encontrou dificuldade? Se a resposta anterior foi sim, como superou as dificuldades encontradas?).

Figura 3 - Aprendizagem do trabalho de braços (a) e o Trabalho de Respiração (b).

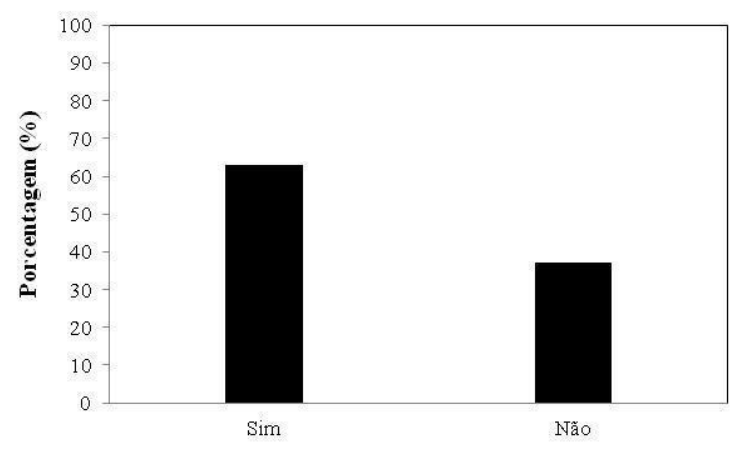

(a)

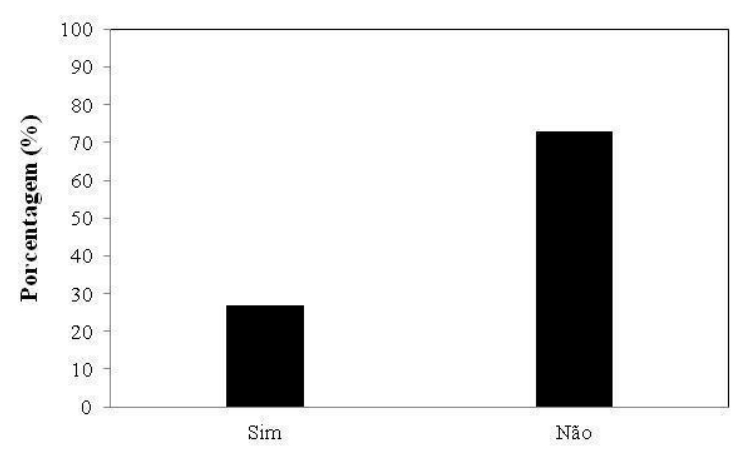

(b)

Dos questionados da Figura 3 (a) 63\% disseram que sim, onde E3, E4, E6, E7, E9, E10 e E11 argumentaram que Coordenação motora; Treinando; Costas e Borboleta. Costas, como a flutuação não é tão boa, fica difícil manter a propulsão dos braços com técnica. No Borboleta falta técnica e força; Crawl. Liga só um braço; Borboleta. Pensamento positivo aos benefícios musculares que teria; Crawl. Por que falta coordenação motora e Ainda não aprendi. Além disso, 37\% disse que "Ainda não está trabalhando com movimento de braços e Não apresentou dificuldades". 
Dos resultados da Figura 3 (b) 27\% indicaram que sim e E1, E10 e E11, dizendo que "Dificuldades em manter respiração na água; Crawl. Estou Praticando e Na hora de respirar eu perco o equilíbrio”. 73\% responderam que não, onde E2, E3, E4, E5, E6, E7, E8 e E9 argumentando que "Ainda está sendo trabalhado na fase inicial, sem maior complexidade; Foi uma etapa tranquila; Não teve dificuldade em fazer; Executa o exercício facilmente; A respiração do nado Crawl pegou rápido e Não encontrou dificuldade.

É possível constatar que a dificuldade de aprendizagem da técnica da braçada de algum dos nados na fase inicial de adaptação ao meio líquido, sobretudo que este aluno por ainda está aprendendo, irá executar essa etapa de forma rudimentar. Segundo Unesco (2013) o desenvolvimento motor ocorre de forma progressiva durante toda a vida do ser humano, iniciando-se na sua concepção e cessando somente na sua morte; por outro lado, esse processo também pode sofrer regressões (DA SILVA \& FALCÃO, 2018).

Para técnica da braçada dos nados, é possível constatar que a dificuldade estava em manter o corpo em decúbito dorsal na superfície da água, mantendo o corpo em sustentação e assim executando o nado com maior facilidade, além de que aparentemente alguns indivíduos estavam aperfeiçoando suas técnicas para melhor execução do nado, como é exigido no nado costas, borboleta e crawl.

Observa-se em relação que os indivíduos tiveram dificuldades no aprendizado da respiração por já nesta fase ter uma complexidade e exigir coordenação para ter uma eficiência no ato de nadar. Também, no momento da respiração é necessário que os movimentos dos nados sejam contínuos, mas os alunos não conseguiam e assim perdia paravam o nado e acabavam ficando de pé por perder o equilíbrio na fase de respiração.

De acordo com Apolinário (2016) o nado crawl pode ser classificado como uma habilidade motora contínua, pois compreende movimentos repetitivos, sem início ou fim demarcados; como habilidade motora grossa, pois sua execução demanda recrutamento de vários grupos musculares; e, em relação às condições do ambiente, como habilidade predominantemente aberta, quando executado em ambiente não estável é imprevisível característico de águas abertas (mar, lagos, por exemplo), ou predominantemente fechada, quando realizado em ambiente relativamente estável, característico de piscina.

Já os indivíduos que tiveram facilidade no aprendizado da respiração, destacaram que por estar na fase inicial ainda estão aprendendo a técnica, mas é na vivência e praticando nas aulas semanais em que o indivíduo começa a aperfeiçoar esta técnica e assim vai avançando as etapas. Na Figura 4 (a) mostra a Aprendizagem do estilo completo 
(Em relação à aprendizagem do estilo completo, encontrou dificuldade? Se a resposta anterior foi sim, como superou as dificuldades encontradas?) e (b) (as experiências vivenciadas tem proporcionando o desenvolvimento seu ou de seu filho (a)? Se a resposta anterior foi sim, como superou as dificuldades encontradas?).

Figura 4 - Aprendizagem do estilo completo (a) e o Desenvolvimento a partir das experiências da natação (b).

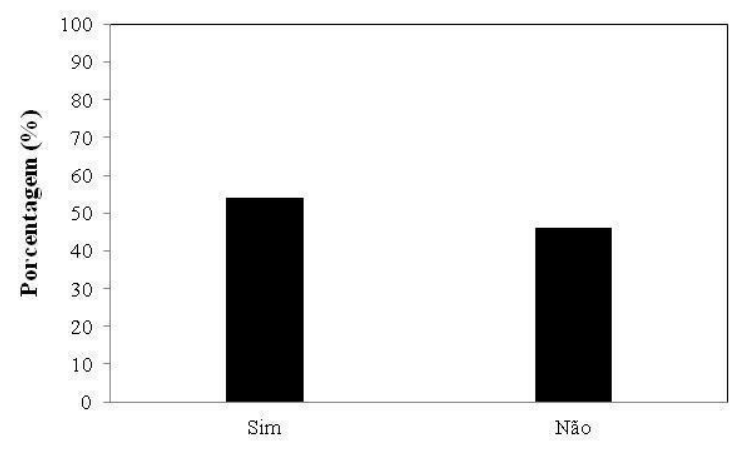

(a)

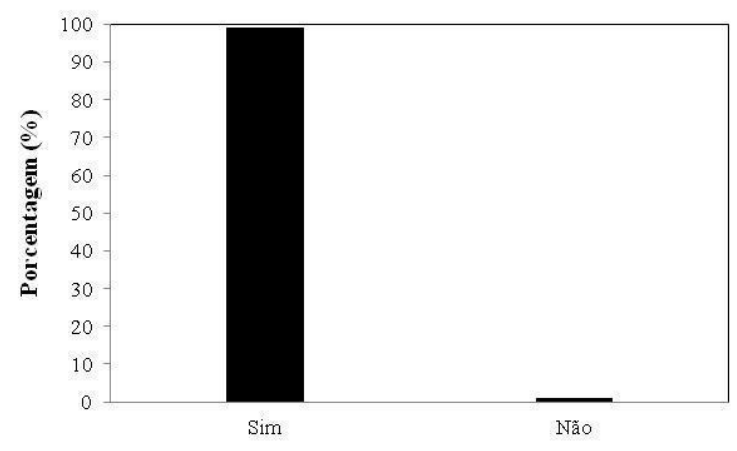

(b)

Na Figura 4 (a) 54\% dos resultados mostram que sim, onde E3, E5, E6, E7, E10 e E11, onde argumentaram que "Não coordena o nado crawl; Borboleta". Devido a complexidade e coordenação do nado; Liga só um braço; Crawl. Praticando; Crawl e Ainda não Domino”. No entanto 46\% justificaram que não onde E1, E2, E4, E8 e E9 "Não teve dificuldade em fazer".

No entanto na Figura 4 (b) 100\% dos resultados indicam que sim, no qual E1, E2, E3, E4, E5, E6, E7, E8, E9, E10 e E11 justificaram que "Participando das aulas com colegas e com força de vontade de passar de touca; A superação ocorreu com incentivo por parte dos professores e dos pais quanto a importância da natação; Superação do medo, coordenação motora e concentração; Superou as dificuldades praticando; Ela tem evoluído, fazendo as aulas $2 x$ na semana e se identificando com exercícios passado pelos professores; Trabalhos de coordenação, braço, perna e respiração; Se desenvolveu bem; Com os estímulos dos professores e Praticando; Ainda tenho dificuldades".

$\mathrm{Na}$ fase de aprendizagem do estilo completo os indivíduos encontraram dificuldades na execução do nado de maneira global, relatando que a uma necessidade maior de ter a coordenação motora desenvolvida para conseguir suprir a necessidade de se executar o nado, não apenas o nado crawl, mas também, o nado borboleta que aparece como um dos nados simultâneos. 
De acordo com Thame (2010) o desempenho aperfeiçoado se adapta a uma grande variedade de características do contexto de desempenho. Nunca desempenhamos uma habilidade em que todas as condições no contexto do desempenho sejam exatamente idênticas. Os indivíduos que tiveram facilidade na aprendizagem de natação, relatam que não tiveram dificuldades em aprender a respiração sem que alguns indivíduos aprendessem de maneira mais rápida que outras.

Constatou-se que todos os indivíduos do quadro desta pesquisa relataram que, independente das dificuldades na fase inicial e nos outros níveis de natação, conseguem perceber seu desenvolvimento ao longo do tempo movido por desejos de avançar de nível, pela motivação e influência pertinente dos professores que ministram as aulas instigando seus alunos a fazerem o melhor por eles mesmos e à fase de desenvolvimento pela qual estão passando.

De acordo com Haywod (2006) o desenvolvimento é definido por várias características. Primeiro, é um processo contínuo de mudanças na capacidade funcional. Pense na capacidade funcional como na capacidade de existir-viver, mover - se e trabalhar - no mundo real. Esse é um processo acumulativo, em que os organismos vivos estão sempre em desenvolvimento, mas a quantidade de mudanças pode ser mais ou menos observável ao longo da vida.

Mesmo, os indivíduos praticam as aulas mais de 1 vez na semana, fato este, quanto mais os alunos praticam as aulas estarão propensos a se desenvolverem. No entanto, a participação nas atividades propostas é exibida na Figura 5 (a) (Você ou seu filho (a) participa de todas as atividades propostas pelo professor nas aulas de natação? Se a resposta anterior foi sim, como superou as dificuldades encontradas?) e na (b) apresenta a execução dos movimentos iniciais de cada nado (Você ou seu filho (a) executa os movimentos iniciais de cada nado, sendo eles: Pernada e braçada com ou sem auxílio do professor? Se a resposta anterior foi sim, como superou as dificuldades encontradas?).

Figura 5- Participação nas atividades propostas (a) e a Execução dos movimentos iniciais de cada nado (b). 


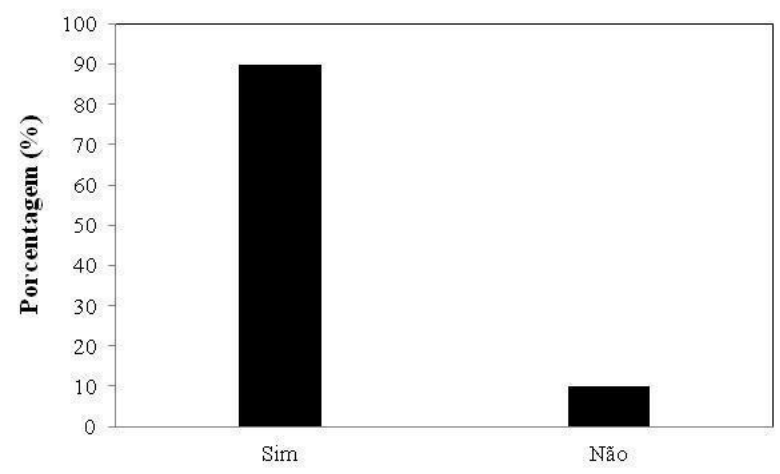

(a)

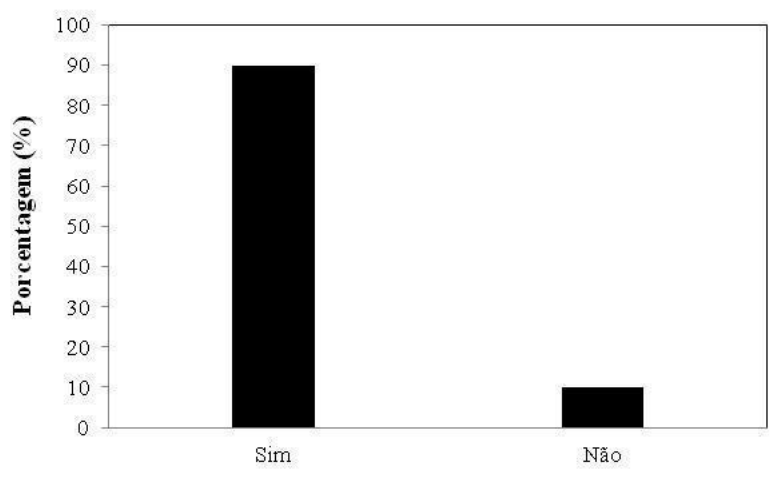

(b)

Dos resultados da Figura 5 (a) 90\% responderam que sim, onde E2, E3, E4, E5, E6, E7, E8, E9, E10 e E11 justificaram que “Com auxílio do professor e com material de apoio; Confiança nos professores, superando o medo, fazendo as atividades propostas com dedicação; Praticando; Praticando os exercícios e comparecendo nas aulas; Participando assiduamente nas aulas; Participa com tranquilidade; Com esforço para baixar meu tempo e Tentando fazer na medida do possível”.

Na Figura 5 (b) $10 \%$ avaliaram negativamente e $90 \%$ disseram que não E1, E2, E3, E4, E5, E6, E7, E8, E9 e E11 onde justificaram que "Participando das atividades em aula e também atividades recreativas; Ele ainda está na fase inicial tendo auxílio dos professores; Confiança nos professores, respeito pela rotina; Praticando; Ganhando autonomia, superando a insegurança com as aulas duas vezes na semana; Meu filho é muito corajoso e quando desafiado, sempre tenta superar suas dificuldades; Ele executa os movimentos; Praticando as aulas; Não tenho dificuldade e Eu tento fazer.

É possível constatar que em relação às atividades a serem feitas durante as aulas propostas pelos professores o indivíduo relatou que não faz, não justificando sua resposta. No entanto, a maioria comentou que executa todas as atividades propostas para serem executadas. Desde a fase inicial os alunos interessados a aprender participam das aulas com auxílio de material para executar os movimentos de cada nado, sendo com auxílio ou sem auxílio do professor.

Neste aspecto, os aprendizes foram com o decorrer das aulas desafiadas pelo professor. Em relação aos desafios que as práticas esportivas propõem. De acordo com Zorzo (2012) descreve que a prática esportiva oferece excelentes oportunidades para o enfrentamento de desafios, para pôr à prova competências, desenvolver habilidades, planejar metas a serem atingidas e participar de atividades variadas e complexas. 
Também, os alunos comparecem nas aulas assiduamente para conseguir desenvolver as habilidades necessárias, tanto para aprendizado como também para o aperfeiçoamento visando estar bem preparado para as competições. Quanto aos movimentos de pernada e braçada de cada nado, um indivíduo respondeu que não, talvez não tenha compreendido a pergunta e também não justificou sua resposta. Na maioria das vezes tiveram facilidade em estarem executando o nado com pernada e braçada, relataram que nas aulas lúdicas, recreativas, com auxílio e orientações dos professores os alunos superaram seus medos, ganharam confiança e a partir disto começaram a se desenvolver e conseguiram executar a braçada junto com pernada após a fase de adaptação ao meio líquido.

O indivíduo após estas intervenções do professor, ganha autonomia para realizar as atividades, sendo corajoso e se desafiando com as atividades propostas nas aulas semanais. Zorzo (2012) argumenta a motivação é um dos temas mais abordados na Psicologia, bem como na Psicologia do Esporte, que procura investigar de modo pertinente os aspectos motivacionais da prática esportiva, tanto em relação ao esporte de competição como do esporte de recreação e lazer, em crianças, jovens e adultos. A motivação enfatizada pelos autores é um elemento que deve estar presente em todo o processo de aprendizagem da natação.

\section{CONSIDERAÇÕES FINAIS}

Após a realização deste estudo apresento as considerações finais que se mostram pertinentes em respeito da problemática, visto que a aprendizagem nas diferentes faixas etárias dos aprendizes mostram variações de acordo com suas vivências desde a infância, em que por falta de estímulos, por não conhecerem o ambiente, por falta de afetividade, nesta fase os alunos acabam tendo medo e insegurança ao se depararem com um volume grande de água como da piscina.

As vivências anteriores à prática da natação podem amenizar e diminuir o período de adaptação dos indivíduos ao ambiente líquido, mas no caso do apresentado na pesquisa, alguns alunos de diferentes faixas etárias não tiveram a experiência de interagir com o meio líquido, criando assim uma rigidez com a água reagindo com medo e falta de confiança para realizar as atividades propostas pelo professor. 
Assim, os indivíduos aprendizes, mesmo os que não passaram por nenhum tipo de trauma como afogamento ou algo semelhante, tiveram dificuldades em desenvolver as habilidades necessárias para nadar, sendo com ou sem auxílio de variados materiais por não ter oportunidade de vivenciar a prática de banho em piscina ou rios, lagos em sítios.

Na percepção dos aprendizes, os mecanismos que utilizaram para a superação das dificuldades encontradas tanto na adaptação ao meio líquido quanto na aprendizagem da natação foram a participação em todas as atividades em aula e também atividades recreativas propostas pelo professor. Estas atividades possibilitam a construção de vínculos afetivos que reforçam o processo de confiança necessário para a aprendizagem.

A prática das rotinas e atividades propostas pelo professor amplia a construção de autonomia segundo a percepção dos aprendizes. Quando desafiados procuram superar as suas dificuldades. Ainda aumentar a frequência semanal das aulas é outra forma que os aprendizes encontram de superar as dificuldades.

Nas diferentes faixas etárias, há dificuldades em se adaptar ao meio liquido desde os bebês com três anos de idade aos adultos com setenta e cinco anos de idade. Elas diferem em relação ao nível de desenvolvimento motor, à habilidade de execução e coordenação dos movimentos, em reação às experiências pregressas de cada um e ao desenvolvimento de fobias em relação a elas.

\section{REFERÊNCIAS}

AMARAL, A. C., TABAQUIM, M. L. \& LAMÔNICA, D. A. Avaliação das habilidades cognitivas, da comunicação e neuromotoras de crianças com risco de alterações do desenvolvimento. Revista Brasileira de Educação Física e Esporte, vol. 11, p. 185-200, 2005. Disponível em https://mgbdownloads.s3-sa-east1.amazonaws.com. Acesso em novembro de 2019.

APOLINÁRIO, M. R. Nado crawl: associação entre coordenação e desempenho de nadadores. 2005. Tese de Doutorado da Universidade de São Paulo. Disponível em https://scholar.google.com.br. Acesso em maio de 2019.

CATTEAU, R. \& GAROFF, G. O ensino da natação. $3^{\circ}$ Edição, Editora Manole, São Paulo, SP, 1990.

CORREIA, C. K., WAMOSY, R. M. G., DE ARRUDA, E. H. Z., DUTRA, A., ROESLER, H., PEREIRA, S. M. Quais os efeitos da natação para crianças e adolescentes? Revisão sistemática de literatura. Arquivos de Ciências do Esporte, v. 7, n. 1, 2019. 
COSTILL, D. L., MAGLISCHO, E. W., RICHARDSON, A. B., SWIMMING. LONDON: Blackwell Science, 1992.

DA SILVA, C. G. P. \& FALCÃO, H. T. A relevância da natação no desenvolvimento psicomotor em crianças de 3 a 6 anos. Cadernos UniFOA, v. 6, n. 2 Esp, p. 85-98, 2018.

DE AZEVEDO, E. B. \& FERREIRA, V. As implicações da especialização precoce na natação. Revista de Trabalhos Acadêmicos da FAM, v. 5, n. 1, 2020.

DE CARVALHO, M. V. P. \& MACIEL, R. M. Os Benefícios da Natação no Desenvolvimento das Crianças e Adolescentes. Revista Saúde e Educação, v. 3, n. 1, p. 53-69, 2018.

DE LIMA, W. U., BORGES, G. \& RASO, V. Idade cronológica de acordo com o nível de aprendizagem em natação. Revista Brasileira de Ciência e Movimento, v. 16, n. 2, p. 65-72, 2009. Disponível em https://bdtd.ucb.br. Acesso em maio de 2019.

DE MELO, J. M. P., SOUZA, J. R., LIMA, R. K. V., DA SILVA, S. L., \& DE OLIVEIRA SANTOS, G. Benefícios da natação para crianças e adolescentes. Brazilian Journal of Development, v. 6, n. 8, p. 62511-62519, 2020.

DE OLIVEIRA, A. \& DA SILVA, L, A. Natação estilo crawl: uma sugestão de ensino para facilitar o aprendizado das aulas de natação. Anais do Seminário de Educação, Conhecimento e Processos Educativos, v. 1, 2015. Disponível em http://periodicos.unesc.net. Acesso em maio de 2019.

DE SIMONE, I. I. S. Natação e seus benefícios, 2017. Disponível em https://repositorio.pgsskroton.com.br/bitstream. Acesso em maio de 2019.

DE VARGAS, J. L. B. \& FRANKEN, M. Efeito das aulas de natação escolar na adaptação ao meio aquático em crianças. Arquivos de Ciências do Esporte, v. 7, n. 4, 2020.

DURAN, M. Aprendendo a nadar em ludicidade. São Paulo: Phorte, 2005.

ESTEVES, C. M. Adaptação ao meio aquático: determinar o grau de aquisição das competências de adaptação ao meio aquático de crianças na educação préescolar, em contextos de ensino com diferentes profundidades da piscina. 2018. Dissertação de Mestrado da Escola Superior de Educação de Coimbra. Disponível em www.comum.rcaap.pt. Acesso em julho de 2019.

FERNANDES, J. R. P. \& LOBO DA COSTA, P. H. Pedagogia da natação: um mergulho para além dos quatro estilos. Revista Brasileira de Educação Física e Esporte, v. 20, n. 1, p. 5-14, 2006. Disponível em https://mgbdownloads.s3-sa-east1.amazonaws.com. Acesso em maio de 2019. 
FREIRE, M. \& SCHWARTZ, G. M. Atividades lúdicas em meio Líquido: aderência e motivação à prática regular de atividades físicas. EFDesporte.com, revista digital. Buenos Aires, 10 Edição, n. 83, abril 2005b.

GAllahuE, D. L. \& OZMUN, J. Compreendendo o Desenvolvimento Motor. São Paulo: Phorte, 2005.

GIL, A. C. Como elaborar projetos de pesquisa. 4 Edição São Paulo: Atlas, 2008.

GOMES, W. D. Natação: uma alternativa metodológica. Rio de Janeiro: Editora Sprint; 1995.

GRECO, P. J. \& BENDA, R. N. Iniciação esportiva universal: da aprendizagem motora ao treinamento técnico. Belo Horizonte: UFMG, MG, 1998.

HAYWOOD, K. M. \& GETCHELL, N. Desenvolvimento Motor ao Longo da Vida, 6a Edição. Artmed Editora, 2016. Disponível em: https://scholar.google.com.br. Acesso em maio de 2019.

HEISE, A. \& LIMA, A. P. W. Citopatologia convencional e Citologia em meio líquido: uma revisão integrativa. Revista Saúde e Desenvolvimento, v. 10, n. 5, p. 208 $221,2016$.

MACHADO D. C. Natação: iniciação ao treinamento. São Paulo: Editora Pedagógica e Universitária Ltda, 2006.

MAGLISCHO, E. W. Nadando ainda mais rápido. São Paulo: Manole, 1999. Acesso em http://www.eeffto.ufmg.br/eeffto/DATA/defesas/20180129081034.pdf. Acesso em maio de 2019.

MANSOlO, A. C. Estudo Comparativo do Aprendizado da Natação (estilo crawl) Entre crianças de Três a Oito Anos de Idade. Universidade de São Paulo, Escola de Educação Física. São Paulo, 1986.

MARTINS, V., SILVA, A. J., MARINHO, D. A. \& COSTA, A. M. Desenvolvimento motor global de crianças do $1^{\circ}$ ciclo do ensino básico com e sem prática prévia de natação em contexto escolar. Motricidade, v. 11, n. 1, p. 87-97, 2015.

NIESWALD, B., NIESWALD, B. H., ACOSTA, G. S., MENEZES, D. R. R., SALVADOR, J. L. R. \& DO REGO, S. G. (2019). Ensino da Natação: Uma Reflexão Docente do Aprender Para Ensinar. Anais do Salão Internacional de Ensino, Pesquisa e Extensão, 11(2).

PRADO, L. Adaptação ao meio líquido. 2005. Disponível em http://www.aquabarra.com.br/artigos/adaptacao. Acesso em maio de 2019.

ROSA NETO, F. Manual de avaliação motora. Porto Alegre: Artmed; 2002. 
SABINO. C. D. H. ESTUDO DO NADO PEITO: análise crítica da literatura, 2013. Disponível em: http://www.eeffto.ufmg.br. Acesso em maio de 2019.

SILVA, L. P. Desenvolvimento motor em crianças praticantes e não praticantes de atividades lúdicas aquáticas. Jornal Internacional Biociências, v. 1, n. 2, 2016. Disponível em: http://www.ojs.ufpi.br. Acesso em: maio de 2019

SILVEIRA, R. P. Coordenação do nado borboleta: estudo piloto sobre os efeitos da velocidade de nado e das ações inspiratórias. Revista Brasileira de Ciências do Esporte, v. 34, n. 2, 2011. Disponível em: http://www.scielo.br . Acesso em maio de 2019

TEIXEIRA, J. Diferentes Metodologias de Ensino-Aprendizagem da Natação em Crianças de 3 a 4 ANOS. Anais do EVINCI-UniBrasil, v. 1, n. 3, p. 106-106, 2015.

THAME, A. C. F. A reabilitação funcional do membro superior de pacientes espásticos, pós-acidente vascular cerebral (AVC). Revista Neurociências, v. 18, n. 2, p. 179-185, 2010. Disponível em: http://revistaneurociencias.com.br. Acesso em maio de 2019 .

ZORZO, A. L. Z. Motivação para a prática da natação competitiva. 2012. Disponível em https://mgbdownloads.s3-sa-east-1.amazonaws.com. Acesso em maio de 2019

Recebido em: 13 de março de 2020.

Aceito em: 16 de janeiro de 2021. 